\title{
Estereótipos sobre os Idosos: Dissociação entre Crenças Pessoais e Coletivas
}

\author{
Rodrigo de Sena e Silva Vieira ${ }^{1}$ \\ Programa de Pós-Graduação em Psicologia da Universidade Federal de Sergipe, \\ São Cristóvão, SE, Brasil \\ Marcus Eugênio Oliveira Lima \\ Departamento de Psicologia da Universidade Federal de Sergipe, \\ São Cristóvão, SE, Brasil
}

\begin{abstract}
Resumo
Os idosos são cada vez mais representativos na sociedade, seja no exterior ou em nosso país, e suscitam discussões sobre o modo como são concebidos. Este trabalho investiga os estereótipos sobre este grupo formados por estudantes universitários da cidade de Aracaju. Através do conceito de dissociação, buscou-se compreender como se organizam as crenças pessoais e as que são atribuídas à sociedade acerca dos idosos. Uma pesquisa foi realizada com 393 participantes de duas instituições, uma pública e uma privada, a partir de um instrumento autoaplicável que questionava sobre a visão da sociedade e a dos próprios participantes a respeito do grupo. Os resultados mostram uma dicotomia em que as crenças pessoais são majoritariamente positivas, enquanto as crenças coletivas são majoritariamente negativas. Eles são discutidos a partir do conceito de dissociação e das possíveis consequências do quadro, e servem para se pensar o modo como se lida com idosos no cotidiano, assim como sugerem futuras pesquisas.
\end{abstract}

Palavras-chave: Velhice, idosos, estereótipos, dissociação, universitários.

\section{Stereotypes about the Elderly: Dissociation between Personal and Collective Beliefs}

\begin{abstract}
The elderly are increasingly representative in society, whether abroad or in our country, and they raise discussions on how they are conceived. This paper investigates the stereotypes about this group formed by university students in the city of Aracaju. Through the concept of dissociation, we sought to understand how personal beliefs and those assigned to the society about the elderly are organized. A survey was conducted with 393 participants from two institutions, one public and one private, from a self-administered instrument that questioned about the society's and the participant's vision about the group. The results show a dichotomy in which personal beliefs are mostly positive, while the collective beliefs are mostly negative. These are discussed through the concept of dissociation and the possible consequences of this situation, and serve to think about how we deal with elderly people in daily life, besides suggesting future research.
\end{abstract}

Keywords: Aging, elderly, stereotypes, dissociation, college students.

Endereço para correspondência: Rua Edson Ribeiro 806, Apto. 502, Grageru, Aracaju, SE, Brasil 49025-140. Fone: (79) 8856-6753.E-mail: rodrigossv@gmail.com e meolima@uol.com.br

Trabalho desenvolvido com bolsa de Mestrado cedida pela Capes (Coordenação de Aperfeiçoamento de Pessoal de Nível Superior). 


\section{Los Estereotipos sobre las Personas Mayores: la Disociación entre las Creencias Personales y Colectivas}

\section{Resumen}

Las personas mayores son cada vez más representativo en la sociedad, ya sea en el extranjero o en nuestro país, y generar debates sobre la forma en que se ven. Este trabajo investiga los estereotipos acerca de este grupo formado por estudiantes universitarios en la ciudad de Aracaju. A través del concepto de disociación, hemos tratado de entender la forma de organizar las creencias personales y los asignados a la sociedad sobre las personas mayores. Se realizó una encuesta con 393 participantes de dos instituciones, una pública y otra privada, a partir de un instrumento autoadministrado que cuestionó acerca de la visión de la sociedad y los propios participantes sobre el grupo. Los resultados muestran una dicotomía en la que las creencias personales son en su mayoría positivas, mientras que las creencias colectivas son en su mayoría negativos. Ellos se discuten desde el concepto de disociación y las posibles consecuencias de la tabla, y sirven para pensar acerca de cómo tratar con las personas de mayores en la vida diaria, y sugerir futuras investigaciones.

Palabras clave: Envejecimiento, personas mayores, estereotipos, estudiantes universitarios.

O envelhecimento é um fenômeno que, a cada dia, tem se tornado mais relevante na nossa sociedade. O mundo desenvolvido e o Brasil, de modo particular, estão envelhecendo. Dados do Instituto Brasileiro de Geografia e Estatística (IBGE, 2013) mostram que, em 2012, havia 24,5 milhões de pessoas com 60 anos ou mais em nosso país, ou $12,6 \%$ da população; em 2002, eram $9,3 \%$. Projeta-se ainda que, em 2060 , idosos sejam 58,4 milhões, ou 26,7\% de nossa população, uma proporção 3,6 vezes maior que a atual. Os idosos tornam-se um grupo social cada vez mais visado. Nos últimos anos, observamos o surgimento de atividades voltadas a eles, de produtos específicos, de serviços especializados e novas terminologias para se referir ao grupo. Em certo sentido, vivemos um período em que as relações estabelecidas com idosos são um tópico de importância crescente.

Entretanto, apesar de o maior número de idosos poder ser visto como algo positivo, paradoxalmente, também pode ser considerado um problema, seja para os governantes ou para pessoas comuns, que associam aos idosos características negativas (Paschoal, 2011). A esse respeito, Debert (2004) fez uma esquematização do que é marcante sobre as discussões envolvendo o envelhecimento do brasileiro nas últimas décadas, propondo dois modelos para se pensar a questão. O primeiro modelo, que reflete uma imagem negativa, considera elementos como a decadência do idoso, os gastos públicos e a desvalorização do grupo no sistema capitalista. $\mathrm{O}$ segundo propõe que os idosos podem ser ativos e contrapor os estereótipos negativos da velhice ao redefinir sua experiência de vida, passando, inclusive, a serem vistos como uma nova demanda no mercado consumidor.

O interesse deste trabalho é entender quais são e como se organizam essas imagens estereotípicas sobre os idosos. São considerados os elementos que constituem as crenças sobre o grupo e ponderadas as possíveis consequências do quadro. Em seguida, é apresentado um estudo empírico realizado com estudantes universitários que verificou como os estereótipos sobre os idosos se refletem em nossa realidade.

\section{Estereótipos sobre os Idosos}

Uma série de elementos históricos pode ser considerada como constituinte das atuais crenças sobre os idosos. Entre eles, o surgimento de disciplinas como a Geriatria e a Gerontologia, que particularizaram a velhice como uma fase dotada de características específicas, algumas vezes positivas, mas muitas vezes relacionadas a perdas (Silva, 2008); o estabelecimento das aposentadorias, que, se por um lado realçou limitações dos idosos e a necessidade de resguardo, por outro 
os marcou como uma categoria política (Laslett, 1991); ou os produtos da modernidade, como a mudança de tradições familiares e o desenvolvimento de novas tecnologias, que estabeleceram novos padrões de relacionamento e, em certo sentido, marginalizaram indivíduos com idade avançada (Cowgill, 1974; Gonçalves, 2007).

Nesse contexto, observa-se que as crenças sobre os idosos se apresentam, por vezes, de forma ambivalente. Nos Estados Unidos, Palmore (1999) mostrou que os estereótipos sobre esse grupo apontam para tendências positivas e negativas. As negativas tratam de aspectos como doença, impotência ou desinteresse sexual, feiura, declínio mental, doença mental, inutilidade, isolamento, pobreza, depressão, dentre outras. Já as positivas dizem respeito a gentileza, sabedoria, confiabilidade, afluência, poder político, liberdade, juventude prolongada, felicidade etc.

No Brasil, estudos têm encontrado resultados parecidos. Por exemplo, numa análise de conteúdo do Estatuto do Idoso, Justo e Rozendo (2010) propõem que, além de posicionar o idoso como cidadão de direitos, o documento acaba por retratá-lo como um ser frágil, impotente e incapaz de gerir sua própria vida. Noutro trabalho, Souza (2002) analisou diários de notícias de São Paulo e Rio de Janeiro publicados entre 1996 e 1998, buscando avaliar o olhar da imprensa a respeito do idoso. Os resultados evidenciaram uma caracterização daquele como pobre e problema social, e revelaram um fato marcante: na maioria das matérias, o depoimento direto dos idosos não foi requerido - o papel coube a suas famílias. Em contrapartida, um estudo sobre as representações sociais encontrou associações positivas, em de termos como "experiência", "sabedoria", "compreensão" e "amor" (Luna, 2010).

Analisando o conteúdo dos estereótipos, Fiske, Cuddy, Glick e Xu (2002) constataram que os grupos sociais são frequentemente representados com ambivalência, baseada na existência de duas dimensões-chave: a competência e a sociabilidade. Estas dimensões, que se relacionam aos grupos em nível alto ou baixo, geram reações específicas sobre eles. Assim, pressupõe-se a existência de quatro tipos de grupo: os competentes e sociáveis normalmente dizem respeito ao endogrupo, gerando orgulho e admiração; os competentes, mas não sociáveis resultam em sentimentos de inveja ou raiva; os incompetentes e sociáveis produzem simpatia e pena; os incompetentes e não sociáveis, por sua vez, são alvos de desgosto.

Os idosos, comumente representados como compreensivos e amáveis, também são associados a concepções negativas de declínio (Justo \& Rozendo, 2010; Luna, 2010). Com efeito, estudos em diferentes perspectivas, como a ativação automática de estereótipos ou seu conteúdo, posicionam-nos entre os grupos considerados incompetentes e sociáveis, juntamente com pessoas deficientes ou portadoras de algum tipo de retardo (Fiske et al., 2002; Zemore \& Cuddy, 2000). Isto também foi observado num trabalho realizado em seis países com diferentes culturas, incluindo aquelas consideradas coletivistas como a japonesa e a coreana (Cuddy, Norton, \& Fiske, 2005). No Brasil, em estudo com participantes de idades variadas, Paula Couto e Koller (2012) também encontraram uma concepção do idoso como alguém mais cordial que competente nas crenças atribuídas à sociedade.

Techio (2011) ressalta que a análise em torno da competência e da sociabilidade associa-se ao status e ao poder dos grupos. Neste sen-tido, aqueles que têm baixo status tendem a ser caracterizados com traços estereotípicos de baixa competência e alta sociabilidade, enquanto os de alto status associam-se às características inversas. Este é um quadro que possibilita a existência de atribuições positivas para grupos socialmente desfavorecidos, embora aquelas não possuam poder de influência para modificar sua condição.

Ainda é possível conceber que os estereótipos organizam-se em formas mais particulares, a partir da aproximação que se tem com o alvo. Taylor (1981) chamou de subtipos uma espécie de ramificação das categorias gerais que aumenta o poder preditivo de nossas crenças. $\mathrm{O}$ desenvolvimento dos subtipos se dá quando surgem informações conflitantes com a categoria geral, ocasião em que podemos agregar novos dados ao estereótipo existente e, com isso, manter sua relevância (Fiske \& Taylor, 1991). Brewer, Dull e Lui (1981) realizaram um estudo em que os participantes organizavam fotos de idosos e suas 
características em categorias, produzindo descrições sobre aqueles que fizeram surgir três subtipos: (a) o subtipo maternal/paternal, descrito como gentil, confiável, sereno e prestativo; (b) o subtipo do estadista, relacionado a um idoso inteligente, competitivo, agressivo e intolerante; e (c) o subtipo do senhor idoso, descrito como solitário, fraco, antiquado e preocupado.

Brewer et al. (1981) lembram, ainda, que os subtipos comumente provocam uma reorganização no conteúdo dos estereótipos. O subtipo maternal/paternal, gentil e prestativo, estaria mais próximo da crença global, caracterizando-se como sociável, mas incompetente, gerando sentimentos de empatia e pena; o subtipo do senhor idoso, fraco e antiquado, é pobre em competência e sociabilidade, causando raiva e desgosto; já o subtipo do estadista, inteligente e competitivo, aproxima-se de grupos de alto status, comumente vistos como não sociáveis, mas valorizados.

Os estereótipos têm fortes consequências sobre a vida das pessoas. Com efeito, a tradição de conceber minorias de forma estereotipada é motivo de implicações danosas àqueles grupos. Nos serviços de saúde, a crença de que idosos estão em decadência ou de que possuem problemas típicos podem fazer com que pacientes tenham queixas negligenciadas ou recebam indicações de tratamentos inadequados (Paschoal, 2011).

A simples exposição a concepções negativas sobre si também pode ter impacto significativo no bem estar dos indivíduos. Tais conteúdos podem prejudicar suas autoestimas e o desenvolvimento de suas reais habilidades, à medida que os indivíduos passam a temer que seus comportamentos confirmem os estereótipos sobre seu grupo (Gergov \& Asenova, 2012). Além disso, a exposição a conteúdos negativos também pode implicar uma série prejuízos imediatos no desempenho de tarefas diversas (Pereira, 2004; Richardson, Karunananthan, \& Bergman, 2011). O cenário inverso também é possível: um estudo longitudinal que acompanhou norte-americanos com idades entre 50 e 80 anos descobriu que indivíduos com percepções mais positivas sobre o envelhecimento tendiam a apresentar maiores cuidados com a saúde (Levy \& Myers, 2004).

Por conta de seus efeitos e de sua indesejabilidade social, os estereótipos negativos nor- malmente são evitados em expressões abertas. Por isso, podem camuflar-se ou abrir espaço para conteúdos socialmente aceitáveis quando os indivíduos são convidados a falar sobre determinados temas. Esse arranjo será abordado a seguir.

\section{Dissociação nas Crenças sobre os Idosos}

As pressões sociais pelo tratamento igualitário das minorias fizeram com que, nos últimos anos, emergissem conteúdos positivos em suas representações (Techio, 2011). Isso não significa, entretanto, que visões depreciativas deixaram de existir. Como abordado anteriormente, por vezes, as crenças positivas dizem respeito a atributos menos valorizados socialmente, mantendo um status de desvalorização para grupos como o dos idosos. A necessidade de tratamento igualitário também pode criar uma tensão ao se exteriorizar concepções sobre os grupos, gerando uma organização particular nas declarações dos indivíduos sobre suas realidades.

Devine (1989) sugeriu que, em nosso processo de socialização, absorvemos as crenças socialmente compartilhadas sobre vários grupos, que se tornam um conteúdo marcante em nossas memórias antes que sejamos capazes de avaliá-las criticamente. Por isso, quando entramos em contato com membros de grupos estereotipados negativamente, este conteúdo é ativado sem que tenhamos controle sobre o episódio. Mas apesar de os indivíduos não terem controle sobre a ativação automática, eles são capazes de forçar sua negação através de avaliações individuais conscientes, o que torna a ativação e a aplicação dos estereótipos episódios distintos (Lima \& Vala, 2004). Partindo dessa concepção, Garcia-Marques (1999) refere a possível existência de uma distinção entre estereótipos culturais e crenças pessoais. Esse choque entre conteúdos coletivos e individuais, identificado por Devine como dissociação de crenças, foi descrito como algo penoso, que requer tempo e esforço para se efetivar, envolvendo três pressupostos: a consciência de que o estereótipo foi mentalmente ativado, a motivação para responder de forma contrária a ele e o uso de recursos cognitivos como a atenção, que tornem possível a substituição da 
resposta automática por uma avaliação pessoal (Bodenhausen \& Macrae, 1998).

O aporte de Devine (1989) permite-nos destacar alguns pressupostos. Primeiramente, que todos os indivíduos são conhecedores dos estereótipos socialmente partilhados; além disso, que é possível evitar a manifestação aberta de estereótipos negativos. A esse respeito, Fazio, Jackson, Dunton e Williams (1995) sugeriram uma classificação que prevê três tipos de indivíduo: o primeiro não possui crenças negativas e, por isso, não ativa conteúdos indesejados frente ao grupo minoritário; o segundo possui crenças abertamente negativas e as exterioriza; o terceiro tipo sente a ativação de avaliações indesejáveis em relação ao grupo minoritário, mas tenta monitorá-las e evitar a negatividade.

Neste trabalho, partiu-se dos pressupostos do modelo dissociativo para investigar os estereótipos sobre os idosos. Por isso, realizou-se um estudo em que se pediu para que os participantes declarassem suas crenças pessoais e o que julgavam ser as crenças coletivas sobre aqueles. Não houve interesse de identificar os participantes que carregavam conteúdos negativos ou positivos - como já sugerido, eles podem, perfeitamente, esquivar-se do que julgam impróprio. Ao invés disso, a estratégia visou apenas a acessar conteúdos socialmente compartilhados, assim como a observar como as crenças coletivas se diferenciam das crenças pessoais declaradas.

\section{Método}

\section{Delineamento}

Este é um estudo do tipo survey exploratório, de caráter quanti-qualitativo.

\section{Participantes}

Participaram do estudo 393 estudantes universitários não idosos, segundo critérios da Organização Mundial da Saúde (OMS, 2005). Entre eles, 282 eram mulheres (72\%) e 111 homens (28\%), com idades entre 17 e 57 anos $(M=25,1$; $D P=8,0)$. Esta quantidade foi estabelecida com base nas necessidades estatísticas para análise de escalas que compunham o instrumento. Par- te dos participantes pertencia a uma instituição pública $(n=203)$ e outra parte a uma instituição particular $(n=190)$. A inclusão foi feita por conveniência e não houve controle de curso ou gênero; as aplicações foram feitas com aqueles que estavam em sala de aula no momento da abordagem. Em relação às idades, aqueles que tinham 60 anos ou mais foram excluídos por fazerem parte do grupo dos idosos.

\section{Instrumento}

$\mathrm{O}$ instrumento utilizado se dividia em três partes. A primeira tratava-se de um questionário estruturado, elaborado pelos pesquisadores, com perguntas abertas e fechadas. A segunda e a terceira partes eram escalas de preconceito. Ele foi entregue impresso em três folhas e era respondido individualmente, com caneta.

No presente trabalho, foram utilizadas duas questões abertas da primeira parte do instrumento que, baseadas no conceito de Devine (1989), investigaram os estereótipos sobre os idosos e a existência de dissociação: "Em sua opinião, que características a sociedade brasileira atribui aos idosos (como a sociedade descreve os idosos)?"; "E você, que características atribui a eles (como os descreve)?". Antes das questões, perguntou-se quantos anos uma pessoa precisa ter para ser considerada idosa; a média obtida foi de 64 anos $(D P=7,1)$.

\section{Procedimentos}

A aplicação da pesquisa foi feita após a realização de um estudo piloto com 15 participantes, visando a avaliar a compreensão do instrumento. No presente estudo, os participantes foram abordados pelo autor em sala de aula, entre dezembro de 2011 e abril de 2012, e convidados a colaborar com uma pesquisa de mestrado em Psicologia, que tratava de como eles percebiam outros grupos. Os que concordavam em participar recebiam o instrumento, eram instruídos a respondê-lo seguindo a ordem original das folhas e devolviam-no assim que terminavam esta tarefa. Não houve rejeições. O tempo médio das aplicações foi de 25 minutos, e 5 participantes foram excluídos posteriormente por possuírem 65 anos ou mais. 
Utilizou-se um Termo de Consentimento Livre e Esclarecido (TCLE) destacável, que os participantes separavam e mantinham consigo antes do início das respostas. Seguiram-se os aspectos éticos previstos na Resolução ${ }^{\circ} 196$ do Conselho Nacional de Saúde (1996), que consiste em diretrizes e normas que regulam as pesquisas com seres humanos. O TCLE apresentava os dados para contato com o pesquisador responsável, além de explicitar o caráter voluntário e anônimo do estudo, garantindo que as participações poderiam ser interrompidas a qualquer momento, por quaisquer motivos. Ao fim das aplicações, era informada a disponibilidade do pesquisador para fornecer os resultados ou responder a quaisquer questões através dos dados informados no TCLE.

\section{Análise dos Dados}

As respostas às duas perguntas foram inseridas no software SPSS for Windows, onde se registraram até três enunciações diferentes por participante. Posteriormente, através da avaliação de três juízes, agruparam-se num mesmo código as respostas consideradas sinônimas, que continham palavras com mesmo radical ou significado muito próximo (Exemplos: "inúteis" e "não servem para nada"; "frágil" e "fragilidade"; "doentes" e "têm problemas de saúde"). Após estas junções, calcularam-se as respostas mais frequentes por meio de estatística descritiva.

Em seguida, para tornar mais clara a diferença entre crenças pessoais e coletivas, os três juízes classificaram as respostas com base em suas valências. Esta classificação resultou em quatro categorias de resposta: positivas, neutras, pseudopositivas e negativas. As positivas e negativas dizem respeito, respectivamente, a qualidades e características aviltantes atribuídas aos idosos. Respostas neutras correspondem a termos não categorizáveis ou que não correspondem a qualidades individuais (exemplo: mal remunerados). É importante demarcar que, sobretudo nas crenças pessoais, alguns termos aparentemente negativos foram categorizados como neutros, como é o caso de "sofridos", "esquecidos" e "excluídos"; isso ocorreu porque tais evocações são um reconhecimento, por parte dos respondentes, de um status desvantajoso dos idosos na sociedade, embora não sejam uma crítica direta do participante ao grupo-alvo. Já nas crenças coletivas, enunciações similares foram inseridas no bloco de respostas negativas: "humilham os idosos", "desrespeitam" ou "têm preconceito contra os idosos", entre outras, não dizem respeito a características, mas são o reconhecimento de ações ou atribuições claramente negativas da sociedade em direção aos idosos.

Por fim, as respostas pseudopositivas são uma categoria criada a partir dos pressupostos teóricos sobre o preconceito contra idosos, que reconhecem atitudes e estereótipos aparentemente positivos e cordiais que podem resultar em consequências danosas aos indivíduos, como sua desqualificação enquanto adultos (Nelson, 2009; Palmore, 1999). Como exemplos dessas categorias, entre as enunciações positivas obtivemos termos como: "amorosos", "experientes", "merecem respeito", "exemplares", "aconselhadores", "úteis". Entre as enunciações negativas, "doentes", "frágeis", "lentos", "descuidados com a higiene", "chatos", "inúteis". Entre as pseudopositivas, "crianças crescidas", "inocentes", "devem descansar", "precisam de ajuda/ cuidados". E entre as crenças neutras, "idade avançada", "cada um tem seu jeito", "iguais a mim". A partir desta classificação, obteve-se acesso às frequências totais de respostas positivas, negativas, pseudopositivas e neutras.

\section{Resultados}

A primeira pergunta tratou das crenças atribuídas à sociedade: "Em sua opinião, que características a sociedade brasileira atribui aos idosos (como a sociedade descreve os idosos)?"; obtiveram-se 95 respostas distintas, num total de 637 enunciações. Entre as 20 respostas mais frequentes, observa-se que 15 foram enunciações consideradas negativas sobre os idosos: "inúteis, incapazes, estorvo, frágeis, excluem os idosos, desrespeitam os idosos, doentes, improdutivos, dependentes, chatos, têm preconceito contra eles, um gasto, inaptos, sem valor". Além destas, duas foram enunciações neutras: "velhos, aposentados"; duas foram pseudopositivas: "precisam de ajuda/ cuidados, precisam de atenção"; e apenas uma foi considerada positiva: "merecem mais respeito". 
Este resultado revela que, na atribuição das crenças coletivas, os participantes construíram uma concepção fortemente negativa sobre os idosos que, considerando o modelo do conteúdo dos estereótipos (Fiske et al., 2002), parece posicionar o grupo nas dimensões de baixa competência e baixa sociabilidade. Trata-se de um quadro distinto do que verificaram Paula Couto e Koller (2012), cujo estudo apontou para crenças coletivas que posicionam os idosos como incompetentes, mas sociáveis.

Houve um contraste, entretanto, nas respostas à segunda pergunta, que tratou das crenças pessoais dos participantes: "E você, que características atribui a eles (como os descreve)?"; obtiveram-se 96 respostas distintas e um total de 817 enunciações. Entre as 20 respostas mais frequentes, observa-se que 13 foram enunciações consideradas positivas: "experientes, podem con- tribuir, merecem respeito, sábios, contribuíram para o presente, amorosos, têm conhecimento, guerreiros, amigos, alegres, geram sentimento de carinho, exemplares, maduros". Além destas, três enunciações foram consideradas neutras: "carentes, iguais a mim, idade avançada"; duas foram consideradas pseudopositivas: "precisam de atenção, precisam de ajuda/cuidados, devem descansar"; e apenas uma foi considerada negativa: "frágeis".

Nas crenças pessoais, verifica-se um quadro inverso ao das crenças coletivas. As dimensões de competência e sociabilidade surgem de forma marcante na maioria das respostas mais frequentes, contrastando com as atribuições feitas às crenças coletivas. Estas respostas estão demonstradas na Tabela 1, que exibe $73,9 \%$ do total das crenças coletivas obtidas e $76,6 \%$ do total de crenças pessoais.

Tabela 1

As 20 Respostas Mais Frequentes sobre as Crenças Coletivas e Pessoais de Estudantes Universitários a Respeito dos Idosos

\begin{tabular}{|c|c|c|c|c|c|}
\hline \multicolumn{3}{|c|}{ Crenças coletivas } & \multicolumn{3}{|c|}{ Crenças pessoais } \\
\hline Resposta & Freq. & $\%$ & Resposta & Freq. & $\%$ \\
\hline Inúteis & 72 & 11,3 & Experientes & 144 & 17,6 \\
\hline Incapazes & 54 & 8,5 & Podem contribuir & 58 & 7,1 \\
\hline Estorvo & 31 & 4,9 & Merecem respeito & 56 & 6,9 \\
\hline Frágeis & 29 & 4,6 & Precisam de atenção & 55 & 6,7 \\
\hline Excluem os idosos & 28 & 4,4 & Precisam de ajuda/cuidados & 41 & 5 \\
\hline Desrespeitam os idosos & 26 & 4,1 & Sábios & 39 & 4,8 \\
\hline Doentes & 26 & 4,1 & Contribuíram para o presente & 35 & 4,3 \\
\hline Improdutivos & 22 & 3,5 & Amorosos & 23 & 2,8 \\
\hline Velhos & 22 & 3,5 & Carentes & 23 & 2,8 \\
\hline Precisam de ajuda/cuidados & 21 & 3,3 & Têm conhecimento & 23 & 2,8 \\
\hline Merecem mais respeito & 17 & 2,7 & Iguais a mim & 17 & 2,1 \\
\hline Dependentes & 16 & 2,5 & Guerreiros & 15 & 1,8 \\
\hline Precisam de atenção & 16 & 2,5 & Amigos & 14 & 1,7 \\
\hline Chatos & 14 & 2,2 & Frágeis & 14 & 1,7 \\
\hline Têm preconceito contra eles & 14 & 2,2 & Devem descansar & 14 & 1,7 \\
\hline Um gasto & 14 & 2,2 & Alegres & 13 & 1,6 \\
\hline Inaptos & 13 & 2,0 & Idade avançada & 12 & 1,5 \\
\hline Sem valor & 12 & 1,9 & Geram sentimento de carinho & 11 & 1,3 \\
\hline Experientes & 12 & 1,9 & Exemplares & 10 & 1,2 \\
\hline Aposentados & 10 & 1,6 & Maduros & 10 & 1,2 \\
\hline Total & 469 & 73,9 & Total & 627 & 76,6 \\
\hline
\end{tabular}


Considerando os subtipos de idosos propostos por Brewer et al. (1981), observa-se que as crenças coletivas aproximam-se daquele subtipo descrito como o senhor idoso, solitário e fraco, que parece se associar às dimensões de baixa competência e baixa sociabilidade, gerando sentimentos como raiva ou desgosto. Já as crenças pessoais não parecem encontrar um correspondente direto, uma vez que não há um subtipo caracterizado por alta competência e alta sociabilidade. Este é um resultado que, certamente, se deve à época e, sobretudo, ao contexto distinto em que se formaram as proposições dos autores.

A Tabela 2 demonstra as frequências de todas as respostas obtidas baseadas na classifi- cação feita anteriormente, que as divide entre crenças negativas, neutras, pseudopositivas e positivas. Seguindo o que foi demonstrado na Tabela 1, percebe-se uma clara diferença entre as crenças pessoais e coletivas, em que as respostas negativas concentram-se no que se atribuiu à da sociedade. Além disso, percebe-se que há uma maior incidência de respostas pseudopositivas nas crenças pessoais, o que parece natural, uma vez que, por vezes, esse tipo de enunciação vai ao encontro do que é socialmente desejável. É algo que se aproxima, por exemplo, do conceito de sexismo benevolente, um fenômeno que fortalece o preconceito e a hierarquia entre grupos sem ferir a norma anti-preconceito (Glick \& Fiske, 2001).

Tabela 2

Frequências e Valências das Crenças Coletivas e Pessoais de Estudantes Universitários a Respeito dos Idosos

\begin{tabular}{ccc}
\hline & Crenças coletivas & Crenças pessoais \\
\hline Negativas & 483 & 50 \\
Neutras & 63 & 93 \\
Pseudopositivas & 42 & 137 \\
Positivas & 49 & 537 \\
\hline
\end{tabular}

\section{Discussão}

No estudo realizado, observou-se uma diferença marcante entre o que os participantes declararam ser suas crenças pessoais e as crenças coletivas. Entre as crenças pessoais, enunciações positivas e pseudopositivas se destacam, ao passo que as crenças coletivas compõem-se principalmente de respostas negativas. É preciso realçar que o instrumento utilizado, por requerer declarações explícitas, está suscetível aos efeitos da desejabilidade social. Em que pese o fato de as respostas terem sido dadas de forma escrita e anônima, e não de forma oral, ainda era esperado que os participantes se aproximassem de declarações julgadas desejáveis. Ainda assim, a utilização dos pressupostos do modelo dissociativo apresentou efeitos úteis à pesquisa: a dicotomia entre crenças pessoais e coletivas permitiu que se tivesse acesso a um conteúdo fortemente negativo que talvez não fosse acessado numa única per- gunta que tratasse, por exemplo, apenas das crenças pessoais ou das coletivas. Tendo em vista que os participantes são, eles mesmos, componentes da sociedade, as crenças coletivas certamente refletem uma dimensão importante dos estereótipos formados pelos indivíduos sobre os idosos.

Apesar disso, pelas limitações do método, a divergência entre crenças pessoais e coletivas é característica nesses resultados e, além disso, não é possível identificar aspectos como quais dos participantes compactuam com visões negativas. Ademais, o contraste induzido pelas perguntas utilizadas também pode explicar a menor presença de enunciações que caracterizam os idosos como sociáveis, mas incompetentes, como proposto por Paula Couto e Koller (2012); neste estudo, como se viu, os resultados apontam para extremos de características totalmente positivas ou totalmente negativas.

Ainda no que tange à dissociação, é possível projetar que diferenças na valência entre crenças 
pessoais e coletivas ocorrerão em estudos sobre quaisquer grupos, levando em conta o pressuposto da desejabilidade social. Entretanto, estudos comparativos podem utilizar a dissociação para avaliar o nível de normatividade do preconceito contra grupos específicos. Com efeito, Lima (2011), ao avaliar a dissociação entre crenças coletivas e pessoais sobre índios e negros, concluiu que, apesar de o fenômeno ocorrer em ambos os casos, a dissociação contra os índios é menor que contra os negros, algo que é explicado pelo autor em função do distanciamento psicológico ou da invisibilização daquele grupo em nossa sociedade, de modo que crenças pessoais negativas surgem com maior facilidade.

A respeito das crenças positivas, sobretudo aquelas que se aproximam mais da sociabilidade que da competência, como "amorosos" ou "geram sentimento de carinho", autores como Brown (2010) acreditam que atribuições desse tipo podem preceder, em algum nível, o que se chama de preconceito positivo, um fenômeno aparentemente benéfico, mas que pode contribuir com a manutenção do baixo status de grupos socialmente desvalorizados; isso ocorreria quando os traços positivos mais característicos de um grupo dizem respeito a características que, socialmente, não possuem o mesmo valor de aptidões ligadas à competência. $\mathrm{O}$ mesmo pode ser dito a respeito das citações consideradas pseudopositivas, mais frequentes entre as crenças pessoais, que, como referido, podem aproximar-se do que Glick e Fiske (2001) identificaram no sexismo benevolente.

Sobre as crenças claramente negativas, realçam-se suas possíveis consequências para o grupo-alvo. No caso dos idosos, cada vez mais representativos em nosso país, é possível conceber que a imagem de incompetência ou demasiada fragilidade pode influenciar não apenas as representações daqueles sobre si e suas relações interpessoais, mas também a formação de políticas públicas direcionadas a eles. Com efeito, o conceito clássico de Butler (1969) aponta os estereótipos como componentes fundamentais na constituição do idadismo, o preconceito etário. Entre as consequências deste fenômeno, estão as de nível institucional, que envolvem, entre outros fatores, a discriminação no campo profissional e na busca por emprego, a aposentadoria compulsória, vieses em políticas públicas etc; assim como as de nível societal, observadas através de linguagem, de normas sociais e da segregação baseada na idade (Butler, 2009; Palmore, Branch, \& Harris, 2005). Ainda no campo do preconceito, Palmore (1999) acredita que a imagem de um idoso dependente, carente ou demasiadamente frágil é o ponto de partida para a manifestação de cuidados pseudopositivos, tais quais a fala e o tratamento infantilizado ou o controle excessivo das atividades diárias daqueles indivíduos, o que pode implicar consequências indesejáveis como a limitação precoce de suas capacidades.

Uma reflexão possível sobre os resultados obtidos é o questionamento sobre em que medida eles simplesmente refletem a realidade, tornando exageradas as reflexões sobre o preconceito. A esse respeito, é possível remeter a outros dois clássicos: Sherif (1967) afirma que os estereótipos podem ser apontados como produto de uma relação intergrupal sob o ponto de vista do grupo que os evoca. É uma visão compatível com a de Tajfel (1972) que, ao discutir a influência dos valores na categorização social, afirmou que a proximidade entre os estereótipos atribuídos a um grupo e os conteúdos que este identifica como compatíveis consigo são reflexo da compreensão compartilhada de uma realidade social. Em ambas as proposições, portanto, o contexto social parece sobrepor-se a concepções absolutas sobre a realidade.

Sob um ponto de vista mais restrito, também é possível apontar a existência de um núcleo de verdade em qualquer estereótipo, mesmo que simplificado ou distorcido (Oakes, Haslam, \& Turner, 1994). Entretanto, em diversos cenários, o fato de um estereótipo negativo ser compatível com dados estatísticos não anula a importância de relativizá-lo ou combatê-lo em larga escala. Tomemos como exemplo a associação que se faz entre negros e estereótipos ligados à criminalidade. Numa extensa pesquisa que abrangeu dados de todos os municípios brasileiros com população superior a cem mil habitantes, Resende e Andrade (2011) encontraram forte correlação 
entre a pobreza e a desigualdade social e crimes contra o patrimônio - roubos, furtos, latrocínios, estelionatos etc. Em paralelo a isso, dados de 2010 do IBGE (2011) mostraram que indígenas, pardos e pretos têm rendimento médio mensal consideravelmente inferior aos brancos - considerando brancos ( $\mathrm{R} \$ 1.020)$ e pretos ( $\mathrm{R} \$ 539)$, a diferença proporcional é de quase dois para um. Esses dados nos permitem afirmar que a associação de negros à criminalidade não é absolutamente infundada. Entretanto, isso não diminui a importância de se combater os efeitos negativos decorrentes daquela, uma vez que o quadro afeta, de forma indiscriminada, um contingente diverso de pessoas.

\section{Conclusão}

Este trabalho visou a investigar os estereótipos formados sobre os idosos por estudantes universitários. Partindo do conceito da dissociação, a pesquisa apresentada mostrou que houve uma divisão no modo como os idosos são descritos pelos participantes: enquanto as crenças pessoais se caracterizaram por enunciações positivas em sua maioria, as crenças atribuídas à sociedade apresentaram valência oposta, sendo majoritariamente negativas. Esta dicotomia, embora se deva em parte ao método utilizado, que induz à desejabilidade social por se basear em perguntas abertas, também aponta para a existência de conteúdos claramente negativos que, em algum nível, compõem o imaginário dos indivíduos sobre o grupo social em questão.

Os estereótipos sobre os idosos apresentados, portanto, servem de ponto de partida para se pensar o modo como eles são concebidos na sociedade e, sobretudo, nas consequências dessas visões. A existência de forte dissociação nas crenças sinaliza o reconhecimento, por parte dos participantes, de que há uma norma de desejabilidade que é comum no estudo de diferentes tipos de preconceito. Assim, o conteúdo obtido no presente estudo parece servir de referência para outras frentes de análise, como as representações sociais e o preconceito etário, assim como para estudos que relacionem as crenças a escalas de atitudes ou medidas implícitas.
Para as áreas de conhecimento e intervenção voltadas aos idosos, a diversidade no modo de se pensar o grupo, com concepções positivas, pseudopositivas e negativas, serve para que se reflita sobre como este é tratado no dia-a-dia, de forma que noções aparentemente positivas não se reflitam em práticas que subestimem suas capacidades, e que noções negativas não sejam negligenciadas. Com o aumento populacional do grupo em nosso país, este é um tipo de discussão que precisa estar cada vez mais presente no cotidiano.

\section{Referências}

Bodenhausen, G. V., \& Macrae, C. N. (1998). Stereotype activation and inhibition. In R. Wyer Jr. (Ed.), Stereotype activation and inhibition (pp. 1-51). Mahwah, NJ: Erlbaum.

Brewer, M. B., Dull, V., \& Lui, L. (1981). Perceptions of the elderly: Stereotypes as prototypes. Journal of Personality and Social Psychology, 41(4), 656-670. doi:10.1037/0022-3514.41.4.656

Brown, R. (2010). Prejudice: Its social psychology $\left(2^{\text {nd }}\right.$ ed.). New York: John Wiley \& Sons.

Butler, R. (1969). Age-ism: Another form of bigotry. The Gerontologist, 9(4), 243-246.

Butler, R. (2009). Combating ageism. International Psychogeriatrics, 21(2), 211-211. doi:10.1017/ S104161020800731X

Conselho Nacional de Saúde. (1996). Diretrizes e normas regulamentadoras sobre pesquisa envolvendo seres humanos. Resolução 196. Brasília, DF: Autor.

Cowgill, D. (1974). Ageing and modernization: A revision of the theory. In J. Gubrium, Late life, community and environmental policy (pp. 5467). Springfield, IL: Charles C. Thomas.

Cuddy, A. C., Norton, M., \& Fiske, S. (2005). This old stereotype: The pervasiveness and persistence of the elderly stereotype. Journal of Social Issues, 61(2), 267-285. doi:10.1111/j.15404560.2005.00405.x

Debert, G. (2004). A construção e a reconstrução da velhice: Família, classe social e etnicidade. In A. Neri \& G. Debert (Eds.), Velhice e sociedade (2. ed., pp. 41-68). Campinas, SP: Papirus. 
Devine, P. (1989). Stereotypes and prejudice: Their automatic and controlled components. Journal of Personality and Social Psychology, 56(1), 5-18. doi:10.1037/0022-3514.56.1.5

Fazio, R. H., Jackson, J. R., Dunton, B. C., \& Williams, C. J. (1995). Variability in automatic activation as an unobtrusive measure of racial attitudes: A bona fide pipeline? Journal of Personality and Social Psychology, 69(6), 10131027. doi:10.1037/0022-3514.69.6.1013

Fiske, S. T., Cuddy, A. J., Glick, P., \& Xu, J. (2002). A model of (often mixed) stereotype content: Competence and warmth respectively follow from perceived status and competition. Journal of Personality and Social Psychology, 82(6), 878-902. doi:10.1037//0022-3514.82.6.878

Fiske, S. T., \& Taylor, S. E. (1991). Social cognition ( $2^{\text {nd }}$ ed.). New York: McGraw-Hill.

Garcia-Marques, L. (1999). O estudo dos estereótipos e as novas análises do racismo: Serão os efeitos dos estereótipos inevitáveis? In J. Vala \& V. Alexandre (Eds.), Novos racismos: Perspectivas comparativas (pp. 121-131). Oeiras, Portugal: Celta.

Gergov, T., \& Asenova, I. (2012). Ageism and negative mental tendencies in the third age. Psychological Thought, 5(1), 69-74. doi:10.5964/psyct. v5i1.12

Glick, P., \& Fiske, S. T. (2001). Ambivalent sexism. In M. P. Zanna (Ed.), Advances in experimental social psychology (Vol. 33, pp. 115-18). Thousand Oaks, CA: Academic Press.

Gonçalves, Z. C. (2007). O novo mundo do passa cartões e aperta botões. In T. Negreiros (Ed.), $A$ nova velhice. Uma visão multidisciplinar (2. ed., pp. 57-72). Rio de Janeiro, RJ: Revinter.

Instituto Brasileiro de Geografia e Estatística. (2011). Sinopse do Censo Demográfico de 2010. Rio de Janeiro, RJ: Autor.

Instituto Brasileiro de Geografia e Estatística. (2013). Projeção da população do Brasil por sexo e idade para o periodo 2000/2060. Recuperado em http://www.ibge.gov.br/home/estatistica/populacao/projecao_da_populacao/2013/default. shtm http://censo2010.ibge.gov.br/

Justo, J. S., \& Rozendo, A. S. (2010). A velhice no Estatuto do Idoso. Estudos e Pesquisas em Psicologia, 10(2), 471-489. Recuperado em http://pepsic.bvsalud.org/scielo.php?script=sci arttext\&pid $=$ S1808-42812010000200012\&lng= es\&nrm $=$ iso \&tlng $=p t$

Laslett, P. (1991). A fresh map of life: The emergence of the third age. Cambridge, MA: Harvard University Press.

Levy, B. R., \& Myers, L. M. (2004). Preventive health behaviors influenced by self-perceptions of aging. Preventive Medicine, 39(3), 625-629. doi:10.1016/j.ypmed.2004.02.029

Lima, M. E. O. (2011). Da diferença à indiferença: Racismo contra índios, negros e ciganos no Brasil. In E. M. Techio \& M. E. O. Lima (Eds.), Cultura e produção das diferenças: Estereótipos e preconceito no Brasil, Espanha e Portugal (pp. 217-245). Brasília, DF: Technopolitik.

Lima, M. E. O., \& Vala, J. (2004). Serão os estereótipos e o preconceito inevitáveis? O monstro da automaticidade. In M. E. O. Lima \& M. E. Pereira (Eds.), Estereótipos, preconceito e discriminação: Perspectivas teóricas e empíricas (pp. 41-68). Salvador, BA: Editora da Universidade Federal da Bahia.

Luna, V. (2010). Juventude, velhice e preconceito na perspectiva das representações sociais. In V. Luna \& Z. Nascimento (Eds.), Desafios da psicologia contemporânea (pp. 49-62). João Pessoa, PB: Editora da Universidade Federal da Paraíba.

Nelson, T. D. (2009). Ageism. In T. D. Nelson (Ed.), Handbook of prejudice, stereotyping and discrimination (pp. 431-440). New York: Psychology Press.

Oakes, P. J., Haslam, S. A., \& Turner, J. C. (1994). Stereotypes and social reality. Oxford, UK: Blackwell.

Organização Mundial da Saúde. (2005). Envelhecimento ativo: Uma politica de saúde. Brasília, DF: Organização Pan-Americana da Saúde.

Palmore, E. B. (1999). Ageism: Negative and positive. New York: Springer.

Palmore, E. B., Branch, L., \& Harris, D. (2005). Encyclopedia of ageism. Binghamton, NY: Haworth Press.

Paschoal, S. M. P. (2011). Qualidade de vida na velhice. In E. V. Freitas, Py, L., Neri, A. L., Cançado, F. A. X. C., Gorzoni, M. L., \& Doll, J. (Eds.), Tratado de Geriatria e Gerontologia (3. ed., pp. 99-106). Rio de Janeiro, RJ: Guanabara Koogan. 
Paula Couto, M. C. P., \& Koller, S. H. (2012). Warmth and competence: Stereotypes of the elderly among young adults and older persons in Brazil. International Perspectives in Psychology: Research, Practice, Consultation, 1(1), 52-62. doi:10.1037/a0027118

Pereira, M. E. (2004). Grupos sociais e performance intelectual: $\mathrm{O}$ efeito da ameaça dos estereótipos. In M. E. O. Lima \& M. E. Pereira (Eds.), Estereótipos, preconceitos e discriminação: Perspectivas teóricas e metodológicas (pp. 69-87). Salvador, BA: Editora da Universidade Federal da Bahia.

Resende, J. P., \& Andrade, M. V. (2011). Crime social, castigo social: Desigualdade de renda e taxas de criminalidade nos grandes municípios brasileiros. Estudos Econômicos (São Paulo), 4l(1), 173-195. doi:10.1590/S010141612011000100007

Richardson, S., Karunananthan, S., \& Bergman, H. (2011). I may be frail but I ain't no failure. $\mathrm{Ca}$ nadian Geriatrics Journal, 14(1), 24-28. Recuperado em http://www.cgjonline.ca/index.php/ cgj/article/view/4/2

Sherif, M. (1967). Group conflict and co-operation: Their social psychology. London: Routledge.

Silva, L. (2008). Da velhice à terceira idade: O percurso histórico das identidades atreladas ao processo de envelhecimento. História, Ciências, Saúde-Manguinhos, 15(1), 155-168. Recuperado em www.scielo.br/pdf/hcsm/v15n1/09.pdf
Souza, E. (2002). O idoso sob o olhar do outro. In M. Minayo \& C. Coimbra Jr. (Eds.), Antropologia, saúde e envelhecimento (pp. 191-209). Rio de Janeiro, RJ: Fundação Oswaldo Cruz.

Tajfel, H. (1972). Experiments in a vacuum. In J. Israel \& H. Tajfel (Eds.), The context of social psychology: A critical assessment (pp. 69-119). London: Academic Press.

Taylor, S. (1981). A categorization approach to stereotyping. In D. L. Hamilton (Ed.), Cognitive processes in stereotyping and intergroup behavior (pp. 88-114). Hillsdale, NJ: Erlbaum.

Techio, E. (2011). Estereótipos sociais como preditores das relações intergrupais. In E. M. Techio \& M. E. O. Lima (Eds.), Cultura e produção das diferenças: Estereótipos e preconceito no Brasil, Espanha e Portugal (pp. 21-75). Brasília, DF: TechnoPolitik.

Zemore, S., \& Cuddy, A. (2000). Elderly stereotype contents at the automatic level. Unpublished raw data.
Recebido: 10/06/2014

$1^{a}$ revisão: 06/10/2014

$2^{a}$ revisão: 29/10/2014

Aceite final: 30/10/2014 